\title{
Kinetic and Thermodynamic Study of Oxidative Decolourisation of a Typical Food Dye (Tartrazine) in an Aqueous Environment
}

\author{
${ }^{* 1}$ OKEOLA, FO; ${ }^{2}$ ODEBUNMI, EO; ${ }^{3}$ AMOLOYE, MA; ${ }^{1}$ BABAMALE, HF $;{ }^{1}$ THEMA, \\ $\mathrm{S} ;{ }^{1}$ ABDULSALAM, JO \\ $1 *$ Department of Industrial chemistry, ${ }^{2}$ Department of Chemistry, ${ }^{3}$ Department of Chemical Engineering, University of Ilorin, Ilorin, Nigeria \\ *Corresponding Author Email: okeola.oj@unilorin.edu.ng; okeolaf@yahoo.com; Tel: +2348058749768, +2348038626501
}

\begin{abstract}
The study was carried out to describe the kinetics and thermodynamics of hydrogen peroxide oxidation of a typical food dye (Tartrazine). The effect of different operational factors were investigated spectrophotometricallyat wavelength $460 \mathrm{~nm}$ under pseudo first order reaction. These included concentration of the oxidant and the dye, the $\mathrm{pH}$, ionic strength and temperature of the reacting medium and the presence of transition metal ion as homogenous catalyst. A complete and smooth decolourisation was observed. The results showed that the rate of oxidation of dye increased with increasing in concentration of substrate and oxidant. Increasing in temperature, ionic strength and $\mathrm{pH}$ of the basic reaction medium also raised the reaction rate. The rate of oxidation also increased with increasing in the concentration of Fe (III) ion. Pseudo second order rate constant $\left(\mathrm{k}_{2}\right)$ obtained was $1.95 \times 10^{-3} \mathrm{M}^{-1} \mathrm{~s}^{-1}$ and $3.8 \times 10^{-3} \mathrm{M}^{-1} \mathrm{~s}^{-1}$ in the absence and presence of $\mathrm{Fe}$ (III) ion respectively. The Arrhenius activation energy for the oxidation in the absence and presence of Fe (III) ion were $47.23 \mathrm{kJmol}^{-1}$ and $42 \mathrm{kJmol}^{-1}$ respectively. Other thermodynamic parameters showed entropy of activation $\left(\Delta \mathrm{S}^{\#}\right)$, free energy of activation $\left(\Delta \mathrm{G}^{\#}\right)$ and Enthalpy of activation of the reaction $\left(\Delta \mathrm{H}^{\sharp}\right)$ in the presence of $\mathrm{Fe}$ (III) as $-34.7 \mathrm{JK}^{-1} \mathrm{~mol}^{-1},{ }^{48.4} \mathrm{kJmol}^{-1}$ and 40.30 $\mathrm{kJmol}^{-1}$ respectively. The results in the absence of Fe (III) ion were $-24.6 \mathrm{JK}^{-1} \mathrm{~mol}^{-1}, 51.2 \mathrm{kJmol}^{-1}$ and $44.0 \mathrm{kJmol}^{-1}$ respectively. The relative lower activation energy (Ea),fairly higher negative value of $\left(\Delta \mathrm{S}^{\#}\right)$ and higher $\left(\Delta \mathrm{G}^{\#}\right)$, with higher rate constant in the presence of $\mathrm{Fe}(\mathrm{III})$ ion showed Fe(III) ion enhancement of rate of decolourisation.
\end{abstract}

DOI:https://dx.doi.org/10.4314/jasem.v24i6.12

Copyright: Copyright $(2020$ Okeola $\mathrm{et} \mathrm{al}$. This is an open access article distributed under the Creative Commons Attribution License (CCL), which permits unrestricted use, distribution, and reproduction in any medium, provided the original work is properly cited.

Dates: Received: 27April 2020; Revised: 22May 2020; Accepted: 15June 2020

Keywords: Tartrazine Food dye, Kinetics, Thermodynamics, Hydrogen Peroxidede colourisation,

Nowadays foods and drinks contain various types of additives that are included for different desirable ends (Zeinab et al., 2017). Much studies have been focused on the use of additives and effect on man and his environment (Fonovich et al., 2012). Of course one the most widely used and dangerous additive is food dyes. Food dyes are often added to food stuff and drinks as expected or preferred by consumers in order to supply, intensify or restore the color to create desired colored appearance (Inetianbor et al., 2015). In United State of America, FDC (Food, Drug and Cosmetic) numbers are given to some colorant, for usein foods, drugs and cosmetics especially for synthetic food dyes that do not exist in nature. Also European number, (E no.) are used for all additives for both synthetic and natural approved for food application. (FDA, 2007; Zeinab et al., 2017). These dyes are environmentally persistent and have strong absorption band in the visible light regions. Their presence in bodies of water especially from effluents discharge generally reduces light transmission affecting aquatic biota (Meiden and Khalil, 2010); and Patel et al., 2016). Tartrazine (Tz) focused in this work is a common synthetic lemon yellow azo-dye which is used as food colouring agent. It is a commonly used colour all over the world, mainly for yellow, but can also be used with Brilliant Blue to produce various green shade. Products including Tz are confectionaries, soft drinks, flavor corn chips, cereal (corn flakes) cake mixes pastries, custard powder, ice cream potato chips, yogurt chewing gum, biscuit and many confectionary together with glycerine, lemon and honey product. $\mathrm{Tz}$ is referred in USA labeling as FD \& $\mathrm{C}$ Yellow 5 and European tag as E102. Tartrazine is a water soluble food dye (Magda et al, 2016).Studies have been carried out on the controlling colouring agents and their colouration of aqueous environment. Biological approach (biodegradation) (Ghodake et al., 2011) and chemical methods (such chlorination, ozonation) (Shubha et al, 2014) are frequently used methods for the removal of dyes from aqueous solution. The oxidation process has been a method for the complete decolorization of dye, Harsa et al., in 2018 disclosed that oxidation process based on the generation of very reactive species such as radical ion $(. \mathrm{OH})$ which then oxidizes a broad range of pollutants quickly and non-selectively. This

*Corresponding AuthorEmail: okeola.oj@unilorin.edu.ng; okeolaf@yahoo.com; Tel: +2348058749768, $+2348038626501$ 
research work describes the potential of Hydrogen peroxide in the oxidative decolourisation of tartrazine - a typical food additive. The resulting oxidized product could no longer absorb visible light. The paper deals with kinetics and thermodynamics of oxidation of tartrazine with Hydrogen peroxide in the presence of $\mathrm{Fe}$ (III) ion. Investigation was carried out on the effect of some working factors on the reaction rate during the oxidation process, such as concentration of substrate, oxidant and Fe (III) ion; ionic strength, $\mathrm{pH}$ and temperature of the reaction medium. The knowledge would serve in controlling the colouration of aqueous environment and the reduction of light transition effect on aquatic lives. Besides it could be of benefit to the workers in fishery and aqua culture, food dye industries and those who handle dye for purpose of staining (Falodun et al, 2015)

\section{MATERIAL AND METHOD}

Chemical reagents used in this study were hydrogen peroxide, Iron (III) chloride, tartrazine dye, sodium hydroxide, bicarbonate and sodium chloride salt, hydrochloric acid. They were MERCK and BDH products are analytical grade, they were used as received and where necessary subjected to further purification. Stock solutions of reagents were prepared in deionised water.

The substrates and the oxidant were also prepared in deionised water. The instrument used for this experiment includes spectrophotometer Beckman Coulter $\mathrm{du}$ 730, thermostated water bath and a $\mathrm{pH}$ meter (CrisonMicroph 2000). the weighing balance (mettler p165) was used for all the weighing and thermometer $\left(0-120^{\circ} \mathrm{c}\right)$ was used to monitor the temperature.

Kinetic Measurement: Since change in concentration was monitored with spectrophotometer, the wavelength corresponding to the maximum absorbance $(\lambda \max )$ need to be ascertained from the absorption spectrum. The absorption spectrum of $0.01 \mathrm{M}$ aqueous solution of tartrazine was determined between the wavelength ranges of $410 \mathrm{~nm}-510 \mathrm{~nm}$. Beer's law was verified between $2 \times 10^{-2}$ to $10 \times 10^{-2}$ moldm ${ }^{-3}$ of Tartarazine at $(\lambda$ max $)$ earlier ascertained and a plot of absorbance against concentration was made. Kinetic Measurement were made by preparing different set of reacting mixture. The kinetic runs were performed under pseudo-first order condition with the respective oxidants in excess over dye concentration [oxidant] $>>$ [dye].

Requisite quantity of each reaction mixture constituent was prepared. The reaction was initiated by rapid addition of the measured amount of oxidant solution to the rest reaction mixture and the entire contents were thoroughly mixed. The progress of reaction was monitor following the change in absorbance of $\mathrm{Tz}$ at $\lambda$ max. The specific rates were evaluated for the reaction were obtained from plots of logarithm of absorbance (A) against time $(\mathrm{t})$. The average initial rates $\mathrm{k}_{\text {obs }}$ over three independent measurements were determined by linear regression from the slope of the concentration versus time plots. The rate constants were averages of at least three measurements.

The rate of discoloration reaction was expressed by equations 1, 2 and 3

$$
\begin{array}{ll}
\text { Rate }=\mathrm{k}_{2}[\mathrm{Tz}]^{\mathrm{a}}\left(\mathrm{H}_{2} \mathrm{O}_{2}\right)^{\mathrm{b}} & 1 \\
\text { Rate } & =\mathrm{k}_{\text {obs }}[\mathrm{Tz}]^{\mathrm{a}}
\end{array}
$$

Whereby

$$
\mathrm{k}_{\mathrm{obs}}=\mathrm{k}_{2}\left(\mathrm{H}_{2} \mathrm{O}_{2}\right)^{\mathrm{b}} \quad 3
$$

Wherek $_{2}$ was the rate constant for the bimolecular reaction of $\mathrm{Tz}$ and $\mathrm{H}_{2} \mathrm{O}_{2}, a$ and $b$ were pseudo-order of the reaction with respect $\mathrm{Tz}$ and $\mathrm{H}_{2} \mathrm{O}_{2}$, the absorbance A at $640 \mathrm{~nm}$ was proportional to the concentration of Tz. The slope of the ln A vs time defined the pseudofirst order rate constant $\mathrm{k}_{\mathrm{obs}}$ was determined. The second order rate $\left(\mathrm{k}_{2}\right)$ was obtained from $\mathrm{k}_{2}=\mathrm{k}_{\mathrm{obs}} /$ $\left(\mathrm{T}_{\mathrm{Z}}\right)$.

The effects of the major system parameters on the kinetics oxidation of tartrazine dye such as the concentrations of the dye (tartrazine) and the oxidant $\left(\mathrm{H}_{2} \mathrm{O}_{2}\right)$, ionic strength, $\mathrm{pH}$ and temperature of the solution were determine.

Experiments were also carried out in the presence and absence of $\mathrm{Fe}$ (III) ion to ascertain its catalytic influence of its presence in the reaction mixture. The quantities of testing parameter were varied while maintaining constant the amount of each of all other components in the system.

The kinetic procedure as describe above was then followed and pseudo-first order-order rate constant $\mathrm{k}_{\text {obs }}$ were estimated from the slopes of the $\log$ absorbance versus time plots

\section{RESULTS AND DISCUSSION}

Spectrum of Tartrazine: The Absorption spectrum figure 1 shows the wavelength corresponding to the maximum absorbance $(\max )$ at $460 \mathrm{~nm}$. Verification of Beer's law between from a plot of absorbance against concentration, (Fig 2) gave a straight line graph that passed through the origin with $\varepsilon=3550 \mathrm{dm}^{3} \mathrm{~mol}^{-1} \mathrm{~cm}^{-}$ 3 .

OKEOLA, FO; ODEBUNMI, EO; AMOLOYE, MA; BABAMALE, HF; THEMA, S; ABDULSALAM, JO 


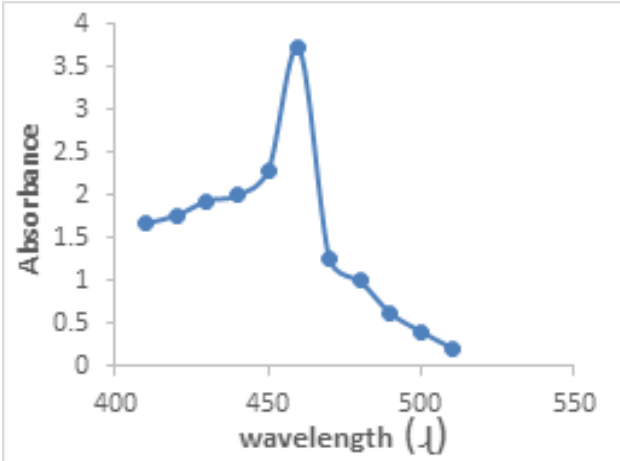

Fig. 1: Calibration curve Absorbance of against wavelength

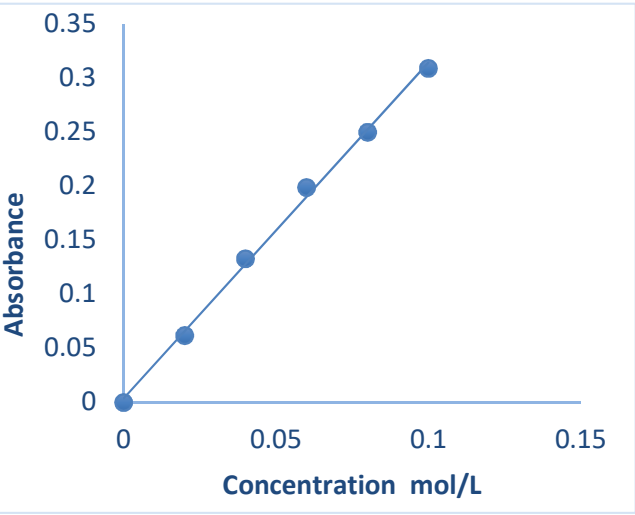

Fig.2: plot of absorbance against concentration tartrazine

Effect of varying Substrate (Dye) Concentration: The dependence of the reaction rate on Tartrazine concentration was measured by maintaining constant the other variables such as the concentration of oxidant solution and the medium ionic strength, temperature, $\mathrm{pH}$. The pseudo first order rate constant were determined at different initial concentration of the dye while the value $\mathrm{k}_{\mathrm{obs}}$ for the oxidation of dye is calculated from the slope the plot of log absorbance against time in the absence and presence of Fe (III) ion (fig 3 and 4 respectively).

The second order rate constant $\mathrm{k}_{2}$ was obtained from the slope of the linear plot of pseudo-first order rate constant, $\mathrm{k}_{\mathrm{obs}}$ against respective dye concentration.

The result of the pseudo first order $\mathrm{k}_{\mathrm{obs}}$ as presented in table 1 shows that the rate of oxidation increased as the concentration of dye increasing both in the absence and presence of $\mathrm{Fe}$ (III) ion in reaction medium The value of pseudo second order rate constant $\left(\mathrm{k}_{2}\right)$ obtained was $1.95 \times 10^{-3} \mathrm{M}^{-1} \mathrm{~s}^{-1}$ and $3.8 \times 10^{-3} \mathrm{M}^{-1} \mathrm{~s}^{-1}$ in the absence and presence of Fe (III) ion respectively indicating the positive effect of Fe (III) ion. Such observation was made in a related work of Gamal et al 2017.

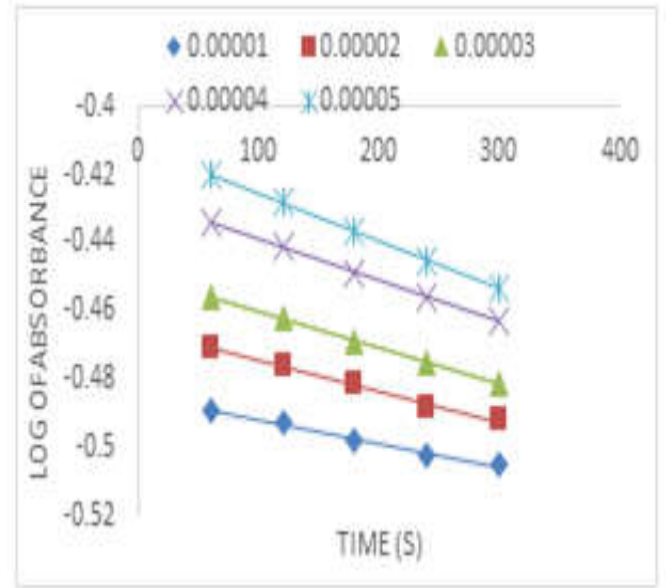

Fig 3 Effect of varying tartrazine dye concentration in the absence of $\mathrm{Fe}$ (III) ion

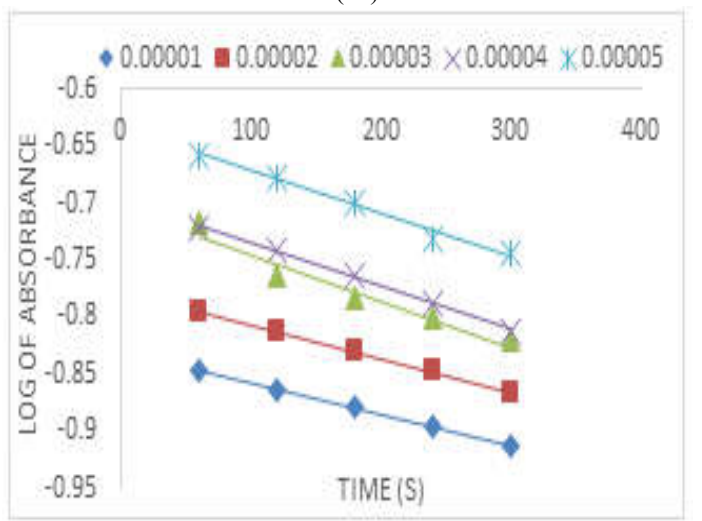

Fig. 4 Effect of varying tartrazine dye concentration in the presence of $\mathrm{Fe}$ (III) ion

Effect of varying oxidant concentration: The reaction was studied as various initial concentration of oxidant while maintaining constant the other variables such as ionic strength, temperature and concentration. The pseudo first order rate constant $\left(\mathrm{k}_{\mathrm{obs}}\right)$ at various concentration of $\mathrm{H}_{2} \mathrm{O}_{2}$ have been evaluated from the slope of the plot of log of absorbance against time. The result of $k_{o b s}$ represented in table 1 show that the first order rate constant show a steady increase with increase in the concentration of $\mathrm{H}_{2} \mathrm{O}_{2}$ solution in the absence and presence of $\mathrm{Fe}$ (III) ion respectively with greater in the presence of $\mathrm{Fe}$ (III) ion

Effect of ionic strength on dye oxidation: The effect of the ionic strength on the rate of oxidation of the dye was studied at constant concentration of $\mathrm{H}_{2} \mathrm{O}_{2}$, dye, and temperature. The concentration of $\mathrm{NaCl}$ was varied between $2.0 \times 10^{-3} \mathrm{M}-10 \times 10^{-3} \mathrm{M}$. Rate constants are evaluated from the slope of the plot of log of absorbance against time of which the result $\mathrm{k}_{\mathrm{obs}}$ arranged in the table 1 .

OKEOLA, FO; ODEBUNMI, EO; AMOLOYE, MA; BABAMALE, HF; THEMA, S; ABDULSALAM, JO 
Table 1. Effect of various parameters on the observed rate constants for peroxide of Tartrazine (a typical dye)

\begin{tabular}{|c|c|c|c|c|c|c|c|}
\hline A & B & $\mathrm{C}$ & D & $\mathbf{E}$ & F & G & $\mathrm{H}$ \\
\hline 1.0 & - & 2.0 & - & 3.0 & 9.80 & - & 1.53 \\
\hline 2.0 & - & 2.0 & - & 3.0 & 9.80 & - & 1.92 \\
\hline 3.0 & - & 2.0 & - & 3.0 & 9.80 & - & 2.30 \\
\hline 4.0 & - & 2.0 & - & 3.0 & 9.80 & - & 2.60 \\
\hline 5.0 & - & 2.0 & - & 3.0 & 9.80 & - & 3.07 \\
\hline- & 1.0 & 2.0 & - & 3.0 & 9.80 & 3.0 & 6.14 \\
\hline- & 2.0 & 2.0 & - & 3.0 & 9.80 & 3.0 & 9.90 \\
\hline- & 3.0 & 2.0 & - & 3.0 & 9.80 & 3.0 & 7.29 \\
\hline- & 4.0 & 2.0 & - & 3.0 & 9.80 & 3.0 & 8.06 \\
\hline- & 5.0 & 2.0 & - & 3.0 & 9.80 & 3.0 & 8.09 \\
\hline 3.0 & - & 1.0 & - & 3.0 & 9.80 & - & 1.54 \\
\hline 3.0 & - & 2.0 & - & 3.0 & 9.80 & - & 1.92 \\
\hline 3.0 & - & 3.0 & - & 3.0 & 9.80 & - & 2.30 \\
\hline 3.0 & - & 4.0 & - & 3.0 & 9.80 & - & 2.68 \\
\hline 3.0 & - & 5.0 & - & 3.0 & 9.80 & - & 3.07 \\
\hline 3.0 & - & - & 1.0 & 3.0 & 9.80 & 3.0 & 2.30 \\
\hline 3.0 & - & - & 2.0 & 3.0 & 9.80 & 3.0 & 3.07 \\
\hline 3.0 & - & - & 3.0 & 3.0 & 9.80 & 3.0 & 3.45 \\
\hline 3.0 & - & - & 4.0 & 3.0 & 9.80 & 3.0 & 4.61 \\
\hline 3.0 & - & - & 5.0 & 3.0 & 9.80 & 3.0 & 5.75 \\
\hline 3.0 & - & 2.0 & - & 1.0 & 9.80 & - & 3.84 \\
\hline 3.0 & - & 2.0 & - & 2.0 & 9.80 & - & 4.98 \\
\hline 3.0 & - & 2.0 & - & 3.0 & 9.80 & - & 5.75 \\
\hline 3.0 & - & 2.0 & - & 4.0 & 9.80 & - & 5.82 \\
\hline 3.0 & - & 2.0 & - & 5.0 & 9.80 & - & 6.91 \\
\hline 3.0 & - & 2.0 & - & 3.0 & 8.70 & - & 6.14 \\
\hline 3.0 & - & 2.0 & - & 3.0 & 9.10 & - & 6.50 \\
\hline 3.0 & - & 2.0 & - & 3.0 & 9.80 & - & 6.52 \\
\hline 3.0 & - & 2.0 & - & 3.0 & 10.60 & - & 7.29 \\
\hline 3.0 & - & 2.0 & - & 3.0 & 11.20 & - & 7.67 \\
\hline 3.0 & - & 2.0 & - & 3.0 & 9.80 & 1.0 & 3.07 \\
\hline 3.0 & - & 2.0 & - & 3.0 & 9.80 & 2.0 & 3.45 \\
\hline 3.0 & - & 2.0 & - & 3.0 & 9.80 & 3.0 & 3.83 \\
\hline 3.0 & - & 2.0 & - & 3.0 & 9.80 & 4.0 & 4.22 \\
\hline 3.0 & - & 2.0 & - & 3.0 & 9.80 & 5.0 & 4.98 \\
\hline
\end{tabular}

$A=[$ Dye $] \times 10^{-3} \mathrm{MFree}$ of $\mathrm{FeCl}_{3}$ in the mixture; $B=[\mathrm{Dye}] \times 10^{-3} \mathrm{M}$ Presence of $\mathrm{FeCl}_{3}$ in the mixture; $\mathrm{C}=[$ Oxidant $] \times 10^{-2} \mathrm{MFree}$ of $\mathrm{FeCl}_{3}$ in the mixture; $\mathrm{D}=[\mathrm{Oxidant}] \times 10^{-2} \mathrm{M}$ Presence of $\mathrm{FeCl}_{3}$ in the mixture; $E=$ Ionic strength $\times 10^{-3} \mathrm{M} ; \mathrm{F}=\mathrm{pH} ; \mathrm{G}=\left[\mathrm{Fe}^{3+}\right] \times 10$

$$
{ }^{5} \mathrm{M} ; \mathrm{H}=k_{\text {obs }} \times 10^{-4} \mathrm{~s}^{-1}
$$

Table 2: Effect of temperature on the rate of oxidation of dye in the absence and presence of $\mathrm{Fe}(\mathrm{III})$ ionat $\mathrm{pH}=9.8,\left[\mathrm{H}_{2} \mathrm{O}_{2}\right]=2 \times 10^{-}$

${ }^{2} \mathrm{M}$, $[$ Tartrazine $\left.]=3 \times 10^{-3},\left[\mathrm{FeCl}_{3}\right]=3 \times 10^{-5}, \mathrm{NaCl}\right]=3 \times 10^{-3}$

\begin{tabular}{lllll}
\hline Temp $(\mathrm{K})$ & A & B & C & D \\
\hline 333 & 1.92 & 0.032 & 3.07 & 0.024 \\
343 & 2.303 & 0.051 & 3.45 & 0.040 \\
353 & 2.69 & 0.073 & 3.83 & 0.060 \\
363 & 3.07 & 0.084 & 4.22 & 0.070 \\
373 & 3.45 & 0.096 & 4.61 & 0.090 \\
\hline
\end{tabular}

$A=k_{o b s} x 10^{-4} s^{-1}$ Free of $\mathrm{FeCl}_{3}$ in the mixture; $B=k_{2} \mathrm{~mol}^{-1} \mathrm{~s}^{-1} ; \mathrm{C}=$ $k_{\text {obs } x} 10^{-4} \mathrm{~s}^{-1}$ Presence of $\mathrm{FeCl}_{3}$ in the mixture; $\mathrm{D}=k_{2} \mathrm{~mol}^{-1} \mathrm{~s}^{-1}$

The oxidation rate which was observed to exhibit a steady increase with increasing in the ionic strength. Such an influence of medium ionic strength on reaction kinetics have been observed (Idris et al., 2015

Effect of $\mathrm{pH}$ on dye oxidation: In the same vein rate constants were determined from varying the of $\mathrm{pH}$ of the reaction mixture from 8.70 and 11.20 while maintaining constant for other variables such as ionic strength, temperature, substrates (dye) and oxidant concentration. The rate constants observed $\mathrm{k}_{\mathrm{obs}}$ at respective $\mathrm{pH}$ are shown in Table 1 . The rate of oxidation have was observed to increase with increasing in $\mathrm{pH}(8.70-11.20)$, the same trend have been observed in the work of Meiden and Khalil in 2010, suggesting that hydroxyl ions may be involved in the rate determining step of the oxidation reaction .

Effect of $\mathrm{Fe}$ (III) ion concentration on dye oxidation: Also rate constants were determined from varying concentration of Fe (III) ion in the reaction mixture of oxidation of dye. The observed rate constants $\mathrm{k}_{\mathrm{obs}}$ was determined at different concentrations of Fe (III) ion As shown in Table 1 shows that The observed rate constants $\mathrm{k}_{\mathrm{obs}}$ increased with increasing in the concentration of $\mathrm{Fe}(\mathrm{III})$ ion

Effect of temperature on rate of dye oxidation: The oxidation of dye were carried out at different temperature from $333-373 \mathrm{~K}$ while maintaining constant concentration $\mathrm{H}_{2} \mathrm{O}_{2}$, dye and $\mathrm{NaCl}$. The pseudo first order rate constants at different temperature were determined differently in the absence and presence of $\mathrm{Fe}$ (III) ion. The observed rate constants increased with increasing in temperature as shown Table 2. The Arrhenius energy of activation (Ea) for the reactions was evaluated from the plot of the logarithm second order rate constant $\mathrm{k}_{2}$, Log $\mathrm{k}_{2}$ against the reciprocal of the temperature $(1 / \mathrm{T})$ for the reaction in the absence and presence of $\mathrm{Fe}$ (III)ion (figures. 5 and 6).his is based on equations 4 and 5 .

$$
\begin{aligned}
& \mathrm{k}_{2}=\mathrm{Ae}^{-\mathrm{Ea} / \mathrm{RT}} \\
& \mathrm{Ink}_{2}=\operatorname{InA}-\frac{E a}{R T}
\end{aligned}
$$

Where $\mathrm{R}=$ gas constant and $\mathrm{Ea}=$ Activation energy

The value of the Arrhenius activation energy Ea, for the oxidative decolourisation of dye (tartrazine) obtained from the slope of the linear plot is 47.23 for uncatalyzed reaction and 42.0 for catalyzed reaction (i.e presence of Fe (III) ion).

The other thermodynamic parameters evaluated include Enthalpy of activation of the reaction $\left(\Delta \mathrm{H}^{\#}\right)$, Gibbs free energy of activation $\left(\Delta G^{\#}\right)$ and the entropy of activation ( $\left.\mathrm{S}^{\#}\right)$ using following appropriate equations 6,7 and 8 (Mortimer et., al. 2002). This is of course in line with a similar work of Ila et al in 2017.

$$
\begin{aligned}
& \Delta \mathrm{H}^{\#}=\mathrm{Ea}-\mathrm{RT} \quad 6 \\
& \Delta \mathrm{G}^{\#}=\Delta \mathrm{H}^{\#}-\mathrm{T} \Delta \mathrm{S} \quad 7
\end{aligned}
$$

OKEOLA, FO; ODEBUNMI, EO; AMOLOYE, MA; BABAMALE, HF; THEMA, S; ABDULSALAM, JO 


$$
\Delta \mathrm{S}^{\#}=2.303 \mathrm{R}\left[\log _{10} \mathrm{~A}-\log _{10} \frac{k T}{h}\right] \quad 8
$$

Where $\mathrm{k}=$ Boltman Constant, $\mathrm{R}=$ Gas Constant and $\mathrm{h}$ $=$ Plank's Constant

Table 2 Effect of temperature on the rate of oxidation of dye in the absence and presence of $\mathrm{Fe}(\mathrm{III})$ ionat $\mathrm{pH}=9.8,\left[\mathrm{H}_{2} \mathrm{O}_{2}\right]=2 \times 10^{-2}$

$\mathrm{M},[$ Tartrazine $\left.]=3 \times 10^{-3},\left[\mathrm{FeCl}_{3}\right]=3 \times 10^{-5}, \mathrm{NaCl}\right]=3 \times 10^{-3}$

\begin{tabular}{lllll}
\hline Temp (K) & A & B & C & D \\
\hline 333 & 1.92 & 0.032 & 3.07 & 0.024 \\
343 & 2.303 & 0.051 & 3.45 & 0.040 \\
353 & 2.69 & 0.073 & 3.83 & 0.060 \\
363 & 3.07 & 0.084 & 4.22 & 0.070 \\
373 & 3.45 & 0.096 & 4.61 & 0.090 \\
\hline
\end{tabular}

$A=k_{\text {obs }} x 10^{-4} \mathrm{~s}^{-1}$ Free of $\mathrm{FeCl}_{3}$ in the mixture; $B=k_{2} \mathrm{~mol}^{-1} \mathrm{~s}^{-1} ; C=$ $k_{\text {obs } x} 10^{-4} \mathrm{~s}^{-1}$ Presence of $\mathrm{FeCl}_{3}$ in the mixture; $D=k_{2} \mathrm{~mol}^{-1} \mathrm{~s}^{-1}$

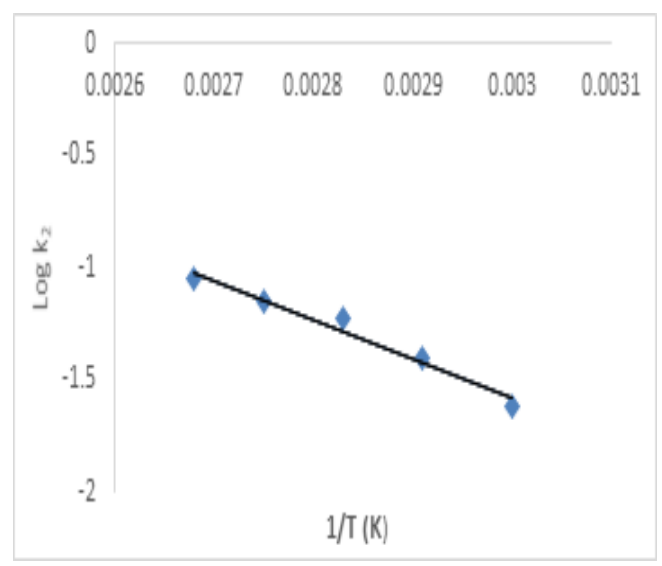

Fig .5A plot of $\log \mathrm{k}_{2}$ against $1 / \mathrm{T}(\mathrm{K})$ for oxidation of tartrazine dye in the absence of Fe (III) ion

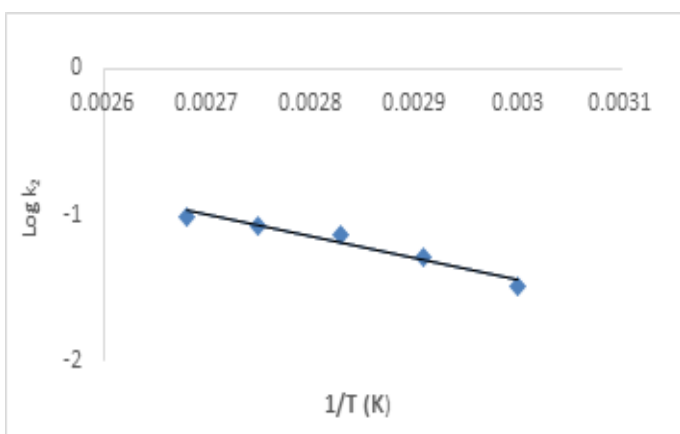

Fig.6 A plot of $\log \mathrm{k}_{2}$ against $1 / \mathrm{T}$ for oxidation of tartrazine dye in the presence of $\mathrm{Fe}$ (III) ion

The value of the activation parameters are presented in table 3 for the decolorisation reaction in the absence and presence of $\mathrm{Fe}$ (III) ion respectively. The difference in the Arrhenius energy of activation (Ea) and a lower value with $\mathrm{Fe}$ (III) ion in reaction mixture showed an enhancement in the decolourisation reaction. The fairly higher negative value of entropy of activation $\left(\Delta S^{\#}\right)$ and free energy of activation $\left(\Delta G^{\#}\right)$ and lower Enthalpy of activation of the reaction $\left(\Delta \mathrm{H}^{\#}\right)$ also indicate this positive role of Fe (III) ion in the reaction medium.

Conclusion: The kinetics of decolorisation of Tartrazine a typical food dye was studied in its oxidation reaction with hydrogen peroxide. The rate of reaction was found to increase with increasing in the concentration of oxidant and the dye. Increasing in temperature, ionic strength and $\mathrm{pH}$ of the reaction medium within the range in this study also increased the rate of oxidation reaction. The presence of Fe (III) ion also serves as positive catalyst. The reaction can therefore be applied appropriately to control the colouration of aqueous environment and can also be useful to those who handle dye for various purpose.

Table 3 Arrhenius and thermodynamic activation parameters for the oxidation of dye in the absence and presence of Fe (III) ion by $\mathrm{H}_{2} \mathrm{O}_{2}$ at $313 \mathrm{~K}$

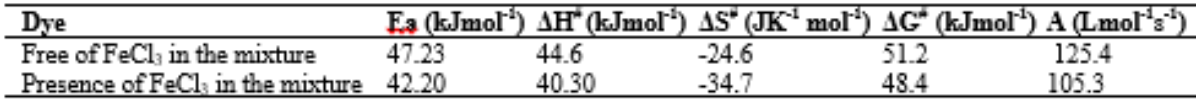

\section{REFERENCES}

Falodun, SO; Idris, SO; Ojo, EO. Iyun, JF. (2015). Kinetics and Mechanism of Indigo Carmine by Permanganate Ion in Aqueous Acidic Medium”. Inter. J. Chem. Biomol. Sci. 1 (4): 255-259.

FDA (2007). Summary of Color Additives for Use in United States in Foods, Drugs, Cosmetics and Medical Devices. FDA
Fonovich, TM (2012). Sudan Dyes: Are they Dangerous for Human Health? Drug and chem. Toxicol. 36 (3): 343-352

Gamal, OE; Said, MT; Heba, MG; (2017). Decolorization and degradation of sunset yellow in aqueous solutions by advanced Fenton oxidation. J. Basic \& Environ. Sci.4: 18-23

Ghodake, GJ; Tamboli, D; Kagalkar, A; Govindwar, S (2011) Decolorization of textile Dyes and

OKEOLA, FO; ODEBUNMI, EO; AMOLOYE, MA; BABAMALE, HF; THEMA, S; ABDULSALAM, JO 
Degredation of Mono azo dye Amaranth by Acinetobacter calcoaceticus NCIM 2890. Indian J. Microbe. 51: 501-508

Harsha, M; Ashwini, N; Ananda, S; Kumara, MN (2018). Oxidative Decolourisation of Food Dye, Quinoline Yellow in the presence of Sodium Hydroxide and in Hydrochloric Acid Catalyzed $\mathrm{By} \mathrm{H}^{+}$:A Kinetic and Mechanistic Approach. Cur. Phy. Chem. 8 (1):10-21

Idris, SO; Tanimu; Iyun, JF: Mohammed, Y (2015). Kinetics and Mechanism of Malachite Green Oxidation by Hypochlorite Ion in Aqueous Acidic Medium. Am. Chem. Sci. J. 5(2): 185-193.

Ila, J; Soma D; Sharma, K; Sharma, V.K (2017) Mechanistic Approach to Kinetic of Oxidation of Monosaccharides by Thallium (III) Acetate. Inter. J. Adv. Res. Sci. Eng. Technol. 4(3) 3495-3500

Inetianbor, JE; Yakubu, JM; Ezeon, SC (2015). Effect of food additives and preservatives on man, a review. Asian J. Sci. Technol. 6(2): 1118-1124
Magda, MSS; Elham, YH; Najat, OAA (2016). "Oxidation and Complexation-Based Spectrophotometric Methods for Sensitive Determination of Tartrazine E102 in some

Mortimer, M. Taylor P. (2002) Chemical Kinetics and Mechanism. $1^{\text {st }}$ Edition, Royal Society of Chemistry, Cambridge, 65-68.

Patel, S; Sharan, M; Chattopadhyay, D (2016). "Effect of Bleaching Agents on Colour Depth of Jute Fabric Dyed with Natural Dyes". J. Textile Sci. Eng. 6(4). ISSN: 2165-8064.

Shubha, JP; Vinutha, K; Dinamani M; Puttaswamy. (2014). "Kinetics and Mechanism of Oxidative Decolorization of Azo Dye acid orange 8 by Sodium N-halo-p-tolenesulfonamides in acid medium: Spectrophotometric approach”. J. Appl. Chem. 7: 40-49.

Zeinab, AA; Ogarite, AY; Mouhiaddine, ME; (2017). Kinetic Study of Acid Blue 1 Discoloration with Persulfate. J. Chem. Technol. Met. 52(2): 812824 